\title{
Proceeding
}

8th INSHS International Christmas Sport Scientific Conference, 5-7 December 2013. International Network of Sport and Health

Science. Szombathely, Hungary

\section{Effect of the neuromuscular activation of knee extensors on vertical jump by using electrostimulation method}

\author{
JIŘí BÍLÝ , JAN CACEK \\ Faculty of Sports Studies, Masaryk University, Czech Republic
}

\begin{abstract}
Bilý, J. \& Cacek, J. (2014). Effect of the neuromuscular activation of knee extensors on vertical jump by using electrostimulation method. J. Hum. Sport Exerc., 9(Proc1), pp.S512-S518. Neuromuscular electrical stimulation is one of the methods of strength development during which there is no voluntary muscle contraction. The aim of this study was to investigate the influence of the neuromuscular activation of knee extensors on vertical jump by using electrostimulation method. Ten healthy trained male students in sportssciences, aged 21-25 years, perform Sargent jump test. They perform two kinds of jump - squat jump and drop jump (42 $\mathrm{cm}$ heigh bench) immediately after electrostimulation and without electrostimulation. Both kinds of jump were performed with and without dynamic stretching. The subjects received electrostimulation for 2 minutes with preset program Explosive power on electrostimulator. We found no significant difference in measuring of heigh of squat jump, where neuromuscular activation by using electrostimulation method was or was not applied. The results showed that heigh of drop jumps significantly increased by using electrostimulation method $+2,7 \%(p=0.005)$ with dynamic stretching and $+3,3 \%(p=$ 0.018 ) without stretching. The results showed that neuromuscular activation by using electrostimulation method (immediately before performance) can have positive effect on heigh of drop jump and so can be added to warm-up part before performance. Using electrostimulation method had no significant effect on squat jump performance. Key words: SQUAT JUMP, DROP JUMP, SARGENT JUMP TEST, ELECTRICAL STIMULATION.
\end{abstract}

Corresponding author. Faculty of Sports Studies, Masaryk University, Czech Republic.

E-mail: struhar@mail.muni.cz

8th INSHS International Christmas Sport Scientific Conference, 5-7 December 2013. International Network of Sport and Health Science. Szombathely, Hungary.

JOURNAL OF HUMAN SPORT \& EXERCISE ISSN 1988-5202

(c) Faculty of Education. University of Alicante

doi:10.14198/jhse.2014.9.Proc1.40

VOLUME 9 | Proc1 | 2014 | S512 


\section{INTRODUCTION}

Electrostimulation (ES) is performed by using an apparatus which sends electrical impulses. These impulses are spread through electrodes to the selected muscles, thereby forcing their activity. Attached electrodes replace the voluntary effort of exercisers, which leads to the delay of fatigue (Lehnert et al., 2010, Dovalil, 2009).

When compared to the traditional workout, by using ES we can act separately on the selected muscle group and $100 \%$ of muscle fibers are activated. Such high numbers can't be achieved during the classical strength training (Grasgruber \& Cacek, 2008).

Several studies confirmed that intensive neuromuscular activation applied immediately before the test of the vertical jump helped to improve performance. For example, Zois et al. (2011) observed that the height of the vertical jump improved by $+2 \%$ after intensive neuromuscular activation using 5 RM (repetition maximum) on the legpress. Needham et al. (2009) concluded that intensive neuromuscular activation (8 repetitions in the squat with a load corresponding to $20 \%$ of body weight) led to a better performance in the vertical jump. Villarreala et al. (2007) documented an improved performance in the vertical jump after several loaded jumps (+4.18\%) and after several repetitions of squats (+2.98\%).

Neuromuscular electrical stimulation is therefore one of possible methods of strength development. Electric impulses are spread without the activation of the control brain center and there is no voluntary muscle contraction. The positive effect of electrostimulation on the increase of muscle strength has been demonstrated by numerous studies (Filipovic et al., 2012).

The objective of this research was to investigate the immediate effect of the neuromuscular activation of knee extensors (via the electrostimulation method) on the performance in the vertical jump.

\section{MATERIAL AND METHODS}

The tested sample included 10 healthy trained male students of sports sciences, aged 21-25 years (see table 1). All the measured subjects were volunteers.

Table 1. Basic characteristics of the tested male subjects

\begin{tabular}{llllll} 
& Valid N & Mean & Minimum & Maximum & Std. Dev. \\
\hline Age $($ year $)$ & 10 & 23.40 & 21 & 25 & 1.51 \\
Height $(\mathrm{cm})$ & 10 & 183.00 & 175 & 191 & 5.44 \\
Weight $(\mathrm{kg})$ & 10 & 83.20 & 75 & 95 & 6.07 \\
Vertical reach $(\mathrm{cm})$ & 10 & 237.50 & 225 & 245 & 6.02 \\
\hline
\end{tabular}

The height of the vertical jump was measured via the Sargent jump test. The Sargent jump test was chosen because it is a very easy and reliable test of explosive strength of lower limbs. The methodology of this test was described by Dudley Allen Sargent more than 100 years ago (Sargent, 1921).

At first, height, weight and vertical reach of the test subjects were measured. The test subjects performed two types of the vertical jump - the squat jump (SJ) and the drop jump (DJ). DJ was performed from a 42 
$\mathrm{cm}$ high bench. SJs and DJs were performed in an order that had been randomly selected. Eight values were collected from each subject, based on the variations in the performed jumps (see figure 1).

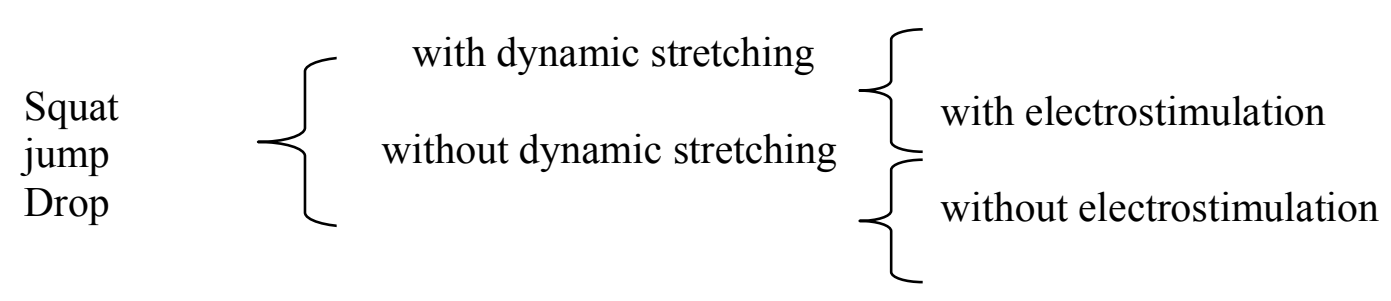

Figure 1. Variantions in the performed jumps

Vertical jumps were executed according to the methodology described by Neumann (2003). The data of the individual jumps were obtained by subtracting the height of the maximum achieved vertical reach from a scale, which was fixed on the wall. The test subjects stood sideways $15 \mathrm{~cm}$ from the wall and they had chalk on the fingers of the dominant hand.

In each variant of the vertical jump, 3 attemps were allowed and the best of them was recorded. There was a 40 seconds rest between the attempts. Both types of jumps were performed with and without dynamic stretching (DS). DS lasted for 5 minutes and was performed in the same place. The test subjects did not perform heavy exercises 2 days before testing. All data were collected by the same researcher.

At the beginning of each testing the test subjects went through a warm-up and pedaled for 5 minutes on a stationary bike. Robbins \& Scheuermann (2008) claim that for optimal performance in the vertical jump, it is appropriate to increase muscle temperature by pedaling on a stationary bike for 5 minutes with a submaximal workload and cadence of $70 \mathrm{rpm}$. Jumps were performed immediately after ES and without ES. Only one type of measurement was performed within a single day. ES was applied in the sitting position at the same time of day.

The electrostimulator (Premium 200, Globus, Italy) was set on the „Explosive strength“ preset program, the level of intensity 30 . The stimulation lasted for 2 minutes during which there occured 7 big muscle contractions. The voltage on the electrodes during a big contraction was $105 \mathrm{~V}$. The electrodes of the electrostimulator were stuck to the thigh by a tape according to the manufacturer's instructions. One big electrode was attached to the proximal part of the thigh and two small electrodes were attached to the inner and outer side of the distal part of the thigh. Electrodes were placed on $\mathrm{m}$. quadriceps femoris as one of most important muscles involving in the vertical jump. Filipovic et al. (2012) analysed 59 studies dealing with electrostimulation and they found out that the $\mathrm{m}$. quadriceps femoris was the most frequently examined muscle.

The obtained data were processed via a statistical program STATISTICA 10 (StatSoft, USA). The Wilcoxon pair test was used to determine the statistical significance between measured performances in the vertical jump with and without electrostimulation. 


\section{RESULTS}

Ten test subjects achieved the following results in the test of the vertical jump: The mean height of DJ without DS was $54.8 \pm 4.49 \mathrm{~cm}$ (mean \pm SD) without ES and $56.6 \pm 4.70 \mathrm{~cm}$ with ES. The mean height of DJ with DS was $55.3 \pm 4.95 \mathrm{~cm}$ without ES and $56.8 \pm 5.47 \mathrm{~cm}$ with ES. The mean height of SJ without DS was $53.5 \pm 4.53 \mathrm{~cm}$ without ES and $54.4 \pm 4.22 \mathrm{~cm}$ with ES. The mean height of SJ with DS was $54.1 \pm$ $5.15 \mathrm{~cm}$ without $\mathrm{ES}$ and $54.3 \pm 4.72 \mathrm{~cm}$ with $\mathrm{ES}$.

The results showed that the height of the DJ was significantly increased by using ES $+2.7 \%(p<0.01)$ with dynamic stretching and $+3.3 \%(p=0.018)$ without stretching. The differences were highly statistically significant (see figures 2 - 5 with box plots). We found no significant differences in the height of the SJ with and without (ES).
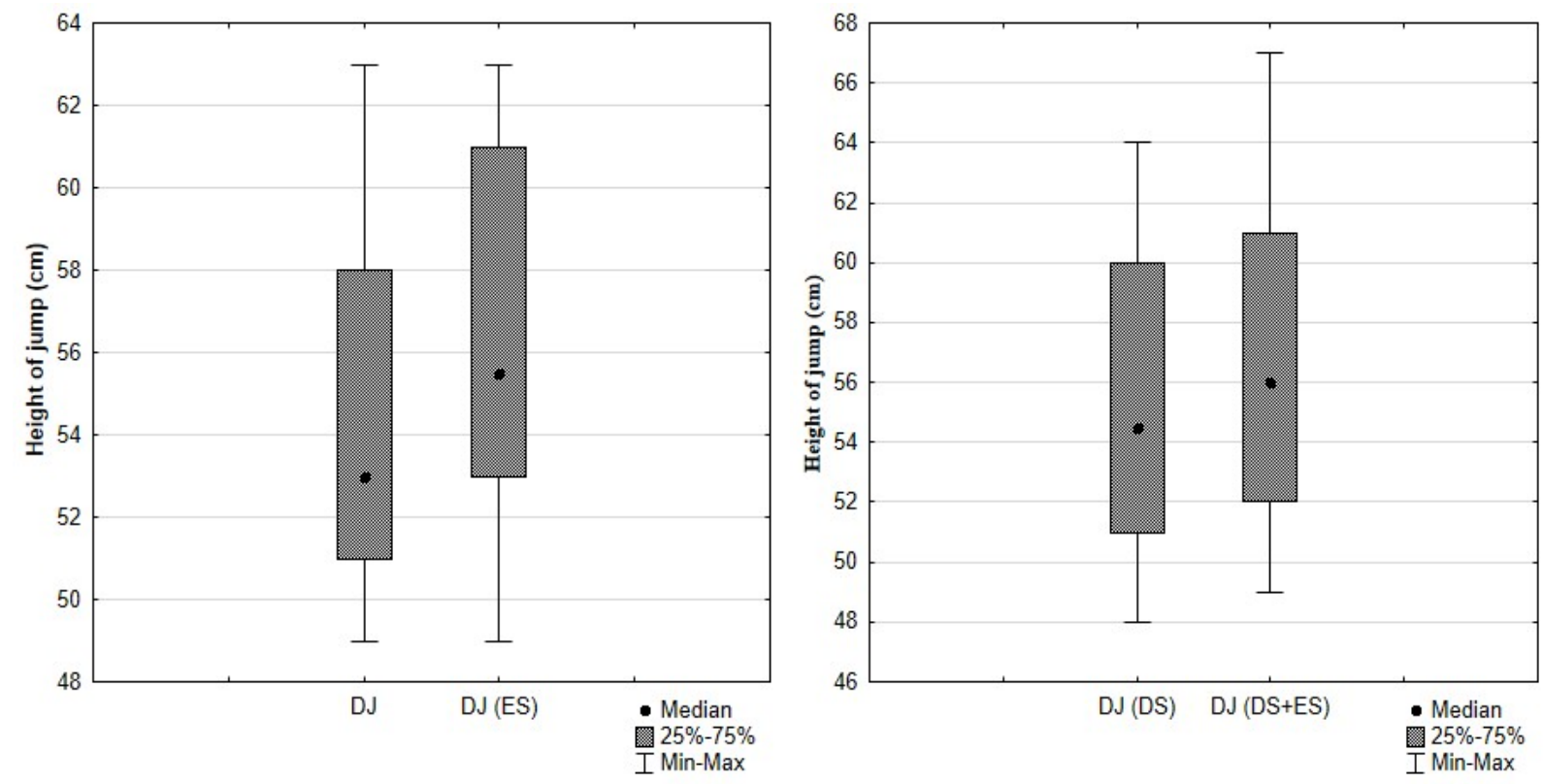

Figure 2. Type of jump: drop jump (DJ) and drop jump after electrostimulation (ES) 


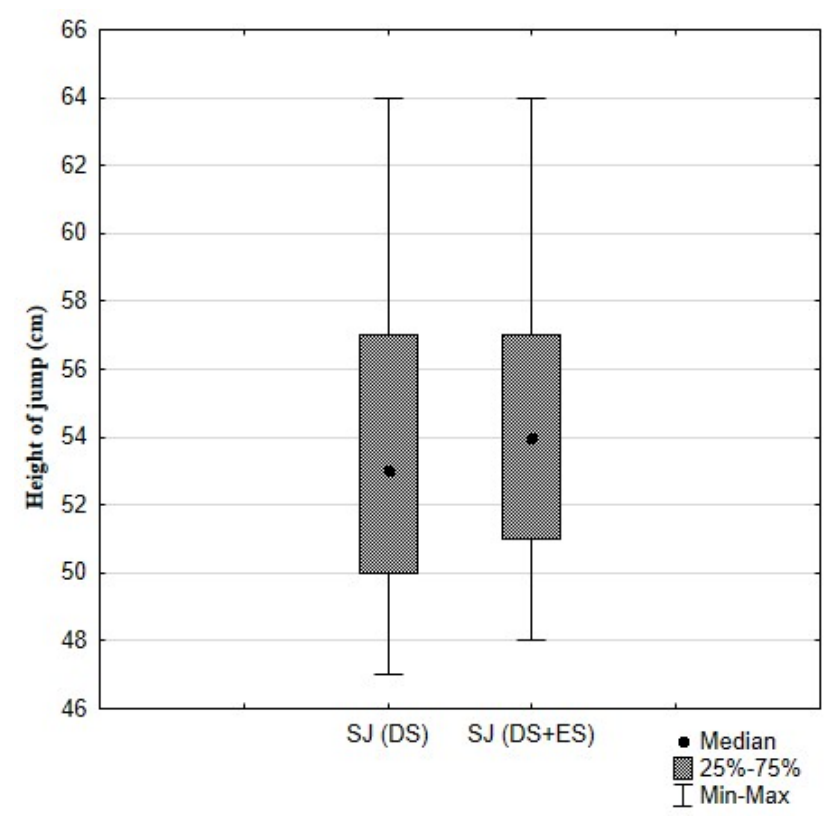

Figure 3. Type of jump: drop jump after dynamic stretching (DS) and drop jump after dynamic stretching and after

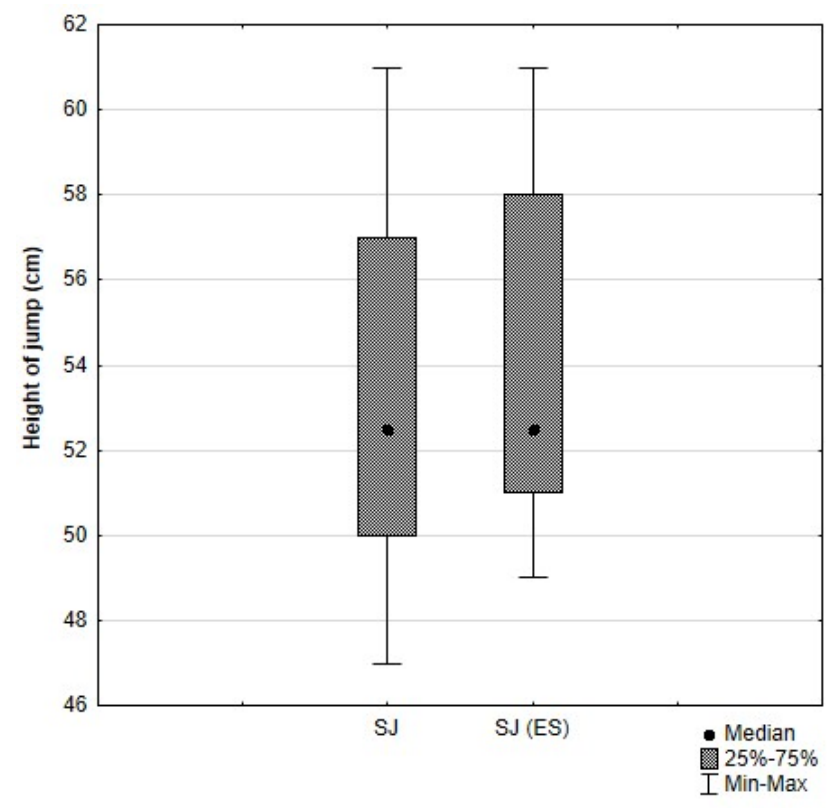

Figure 4. Type of jump: squat jump (SJ) and squat jump after electrostimulation (ES)

\section{DISCUSSION}

Knowing that there exists an immediate effect of ES on performance, we can potentially use it for a better preparation of muscles during the warm-up part before performance. The positive effect of ES on DJ and not on SJ can be attributed to a different structure of movement. 
Muscles are more stressed during DJ than during SJ due to a bigger load. During an exercise with greater resistance, more fast muscle fibers are involved then during an exercise with lower resistance (Bompa, 1999; Kraemer et al., 2012). Palliard et al., (2008) and Hainaut \& Duchateaua (1992) think that fast muscle fibers are activated preferentially during ES. According to Grasgruber \& Cacek (2008) up to $100 \%$ of muscle fibers are activated during ES, so virtually all muscle fibers are prepared for performance. Thus, more muscle fibers are prepared for performance in DJ. This could be the reason, why electrostimulation has a bigger effect on the DJ performance.

The improvement of performance in DJ after ES was $+2.7 \%$ with DS and $+3.3 \%$ without stretching. It is approximately the same improvement like after an intensive neuromuscular activation via loaded jumps, squats or legpress (+2.0 $-4.18 \%$ ), as showed by Zois et al. (2011), Needham et al. (2009) and Villarreala et al. (2007).

One of the limiting factors in this study was the little homogenity of the tested subjects. For further research, it would be necessary to use subjects with the same level of performance in the same sport. Another limitation was the use of ES of the quadriceps femoris only. During a neuromuscular activation without $E S$, the extensors of ankle joints and hip joints are activated, too. There are 8 cables of the electrostimulator available, so at the same time it was possible to stimulate only both $\mathrm{m}$. quadriceps femoris. For a more accurate measurement of the performed jumps, it would be appropriate to use e.g. Force Plate (FiTRONiC, Slovakia) or Force Plate (Kistler Instrument Corp., USA). Two electrostimulators will also be needed for a simultaneous stimulation of ankle extensors and hip extensors.

The finding that an immediate neuromuscular activation via ES has a positive effect on performance may be beneficial for various athletes, who need to increase neuromuscular activation before performance and lack dumbbells or enough space. They can take a small electrostimulator and apply ES in the changing room, at the area for a warm-up etc.

\section{CONCLUSIONS}

Electrostimulation as one of potential methods of strength development, can be applied immediately before performance, which can subsequently lead to a performance improvement. The results of this study showed that neuromuscular activation via electrostimulation caould have a positive effect on the height of the drop jump and hence it could be added to the warm-up part before a sports performance involving vertical jumping. The positive effect of electrostimulation on the squat jump was not demonstrated in this study. It would be necessary to perform more measurements for a thorough clarification of this problem. A further study will also focus on other short-term performances like sprint, long jump, high jump etc.

\section{REFERENCES}

1. Bompa, T.O. (1999). Periodization Training for Sports. Champaign, IL: Human Kinetics.

2. Dovalil, J. (2009). Výkon a trénink ve sportu. Praha: Olympia.

3. Filipovic, A. et al. (2012). Electromyostimulation - a systematic review of the effects of different electromyostimulation methods on selected strength parameters in trained and elite athletes. $J$ Strength Cond Res, 26(9), pp.2600-2614.

4. Grasgruber, P. \& Cacek, J. (2008). Sportovní geny. Brno: Computer Press.

5. Hainaut, K., Duchateau, J. (1992). Neuromuscular electrical stimulation and voluntary exercise. J Sports Med, 14(2), pp.100-113. 
6. Kraemer, W.J., Fleck, S.J. \& Deschenes, M.R. (2012). Exercise physiology: integrating theory and application. Philadelphia: Lippincott Williams \& Wilkins.

7. Lehnert, M. et al. (2010). Trénink kondice ve sportu. Olomouc: Univerzita Palackého v Olomouci.

8. Needham, R.A., Morse, C.I., Degens, H. (2009). The Acute Effect of Different Warm-up Protocols on Anaerobic Performance in Elite Youth soccer players. J Strength Cond Res, 23(9), pp.26142620.

9. Neuman, J. (2003). Cvičení a testy obratnosti, vytrvalosti a sily. Praha: Portál.

10. Paillard, T. et al. (2008). Effects of Two Types of Neuromuscular Electrical Stimulation Training on Vertical Jump Performance. J Strength Cond Res, 22(4), pp.1273-1278.

11. Robbins, J.W. \& Scheuermann, B.W. (2008). Varying Amounts of Acute Static Stretching and Its Effect on Vertical Jump Performance. J Strength Cond Res, 22(3), pp.781-786.

12. Sargent, D.A. (1921). The Physical Test of a Man. American Physical Education Review, Cambridge.

13. Villarreal, E.S.S. et al. (2007). Optimal Warm-up Stimuli of Muscle Activation to Enhance Short and Long-term Acute Jumping Performance. J Appl Physiol, 100(4), pp.393-401.

14. Zois, J. et al. (2011). High-intensity warm-ups elicit superior performance to a current soccer warmup routine. J Sci Med Sport, 14(6), pp.522-528. 